\title{
Women Physicians: Gender and the Medical Workplace
}

\author{
Linda P. Rouse, PhD, ${ }^{1}$ Stephanie Nagy-Agren, MD, ${ }^{2}$ \\ Roberta E. Gebhard, DO, ${ }^{3}$ and Wendy K. Bernstein, MD, MBA, FASA, FAMWA ${ }^{4}$
}

\section{AU2 Abstract}

Understanding the work habits, attitudes, and experiences of women physicians is critical for optimal patient care. An analysis of the medical literature (1990-2017) was undertaken to answer the following question: how are women physicians' work habits viewed within the framework of women's attitudes and experiences? A literature review was performed to identify gaps in past research and help design a longitudinal qualitative analysis of the work experiences and perceptions of women physicians. Published studies were located using search engines, review of article references, consultation with experts, and relevant Mesh terms. Of 1185 listings, 354 studies and abstracts were evaluated, and 44 articles were selected based on cultural context by three reviewers. Four themes emerged-practice styles, productivity, prevailing attitudes, and the workplace environment. Comparing women physicians to male colleagues as a standard for evaluating performance undervalues unique characteristics women bring to medicine. Productivity models typically focus on quantitative measures (e.g., work hours, procedures, and publications) that do not encompass the full scope of patient care. Qualitative data suggest need for further modification in physician training and in practice settings. Studies seldom capture the differing work habits, effects of workplace attitudes, and distinctive obstacles faced by women doctors. Solutions offered have been mainly designed to help women physicians fit into existing gendered workplace environments, but traditionally available "adapt or exit" options in response to challenges faced appear insufficient. A gender equity perspective helps to explain findings and suggests ways to reshape the health care workplace to better understand, utilize, and retain women physicians.

AU3 Keywords: women physicians, medical workplace, gender equity, work life balance, professional practice

\section{Background}

$\mathbf{T}$ HE STRUCTURE OF the medical workplace and practice styles of physicians are evolving to meet the challenges of 21 st century health care. During medical school, residency, and health care delivery, physicians face new expectations from society, health care organizations, and patients. Medicine has evolved from Becker's 1961 description of the "Boys in White." Women are entering medical school in greater numbers and constitute half of all classes, but are not equally represented in all specialties. ${ }^{1,2}$ The quality of health care delivery can be improved by better understanding women physicians as part of a diversified physician workforce.

Previous studies of physicians studied men, assuming no gender differences, or used metrics that emphasized defi- ciencies in performance such as productivity, commitment, or leadership ability. A structure of medical care created for a predominantly white men physician workforce has not recognized the positive values that women bring to health care delivery.

Studies have uncovered obstacles faced by women in reaching similar levels of opportunity, promotion, and recognition as their male colleagues. ${ }^{3,4}$ These challenges stem from a gendered work environment and are perpetuated by limited attention to the adaptation of women to workplace conditions. Understanding practice experiences and attitudes of women physicians is an important step in addressing challenges which prevent women from contributing to their full capacity.

To explore existing research on women physicians, a review of published studies was undertaken with the following

\footnotetext{
${ }^{1}$ Department of Sociology and Anthropology, The University of Texas at Arlington, Arlington, Texas.

${ }^{2}$ Internal Medicine, Virginia Tech Carilion School of Medicine, Salem, Virginia.

${ }^{3}$ Gender Equity Task Force, The American Medical Women's Association, Reston, Virginia.

${ }^{4}$ Department of Anesthesiology and Perioperative Medicine, University of Rochester Medical Center, Rochester, New York.
} 
question: how are women physicians' work habits viewed within the framework of women's attitudes and experiences? As part of a larger research project addressing the work experiences and perceptions of women physicians, a qualitative systematic literature review and narrative synthesis was performed to identify key concepts and gaps in past studies and to determine possible directions for further research. Collection of actionable data will help to create change for women physicians and the delivery of health care.

\section{Methods}

To explore existing research on women physicians, a comprehensive review of published studies (1990-2017) was undertaken from the National Center for Biotechnology Information (NCBI) at the U.S. National Library of Medicine (NLM) using PubMed with the following key words: women physicians, gender difference, practice style, and work-life

T1 balance with relevant Mesh terms (Table 1). Additional studies were sought in OVID, review of article references, and consultation with experts. Of 1185 listings, 354 studies were evaluated and 44 were selected for detailed analysis based on cultural context by three reviewers skilled in this

Table 1. Overview of Literature Search From Published Studies (1990-2017) Regarding Research on WoMen Physicians

Physicians, women were searched with the following mesh terms

Work-life balance

Professional-family relations

Professional-patient relations

Professional practice gaps

Professional practice location

Professional practice

Practice patterns, physicians

Practice management

Professional role

Attitude of health personnel

Leadership

Workplace

Personnel staffing and scheduling

Work schedule tolerance

Shift work schedule

Career mobility

Career choice

Job satisfaction

Workload

Staff development

Health occupations

Relative value scales

Sex distribution

Sex factors

Sexism

Femininity, gender roles

Definitions of Mesh terms, including key words, are available Databases: PubMed, OVID.

Inclusion: published between 1990 and 2017; English language; based on primary research; and peer reviewed.

Exclusion: commentary rather than research based; not in English; and not focused on women physicians' work.

The search generated a list of 1185 articles. Three hundred fiftyfour abstracts were initially selected, and 44 articles were analyzed in full. content area (Table 2). An extraction sheet was utilized to $<\mathrm{T} 2$ elicit study design, results, and central themes from the articles. Articles were retained if peer reviewed and reporting primary research that included women physicians. Articles were excluded if Commentaries and not focused on women physicians. Studies from the United States and Canada were prioritized over other countries, as were studies of generalists over those of subspecialists. Disagreements were resolved by the senior reviewer.

Once studies were selected, attention shifted to data recording. An extraction sheet was utilized to elicit study design, results, and basic concepts from the articles; these were described in paragraph form and later summarized (Table 2). Preliminary description of each study's key features allowed comparison across articles and grouping by similarities and differences. Reviewers independently analyzed the selected articles and compared notes on observed patterns until consensus was reached on four areas emerging as key to understanding experiences of women physicians: practice style, productivity, prevailing attitudes (of and toward women physicians), and work environment. An overview of findings reflecting these themes and deficiencies in the literature is provided (Table 3 ).

\section{Findings-practice style}

Many women physicians differ from their male colleagues in their practice of medicine. Women physicians spend more time with individual patients, which influences the number of patient encounters, patient adherence to preventive and treatment regimens, patient satisfaction, and ultimately patient outcomes. ${ }^{5,6}$

Bertakis et al. used qualitative and quantitative methods to document the impact of gender on physician behavior. ${ }^{7}$ Using the Davis Observation Code (DOC) and controlling for patient health status and gender, they found that women physicians provided more preventive services and devoted more time to psychosocial/family medical history. Patient satisfaction with the women physicians was significantly higher than with the men physicians (4.27 vs. 4.05, $p=0.02$ ).

A randomized study of 509 patients reported that female resident physicians provided increased patient centered care (PCC) using DOC criteria. ${ }^{8}$ Gender concordance between women patients and women physicians resulted in measurable differences in amount of PCC observed, a result confirmed by others suggesting that patients may have predetermined expectations of women physicians based on stereotypical roles or past experiences with women health providers. $^{9}$

Henderson mirrored these results in a multivariate analysis of how patient and physician gender influence preventive screening and counseling. ${ }^{10}$ Using data from the 1998 Commonwealth Fund Survey of Women's Health, a telephone survey of 2256 women and 2094 men, showed that women physicians provided more preventive counseling. Preventive screening and counseling encompassed both gender-specific and nonspecific issues, both general health habits and sensitive topics.

A study of 1857 chronic heart failure patients was evaluated for treatment procedures, comorbidities, New York Heart Association classification, and if a man or woman 


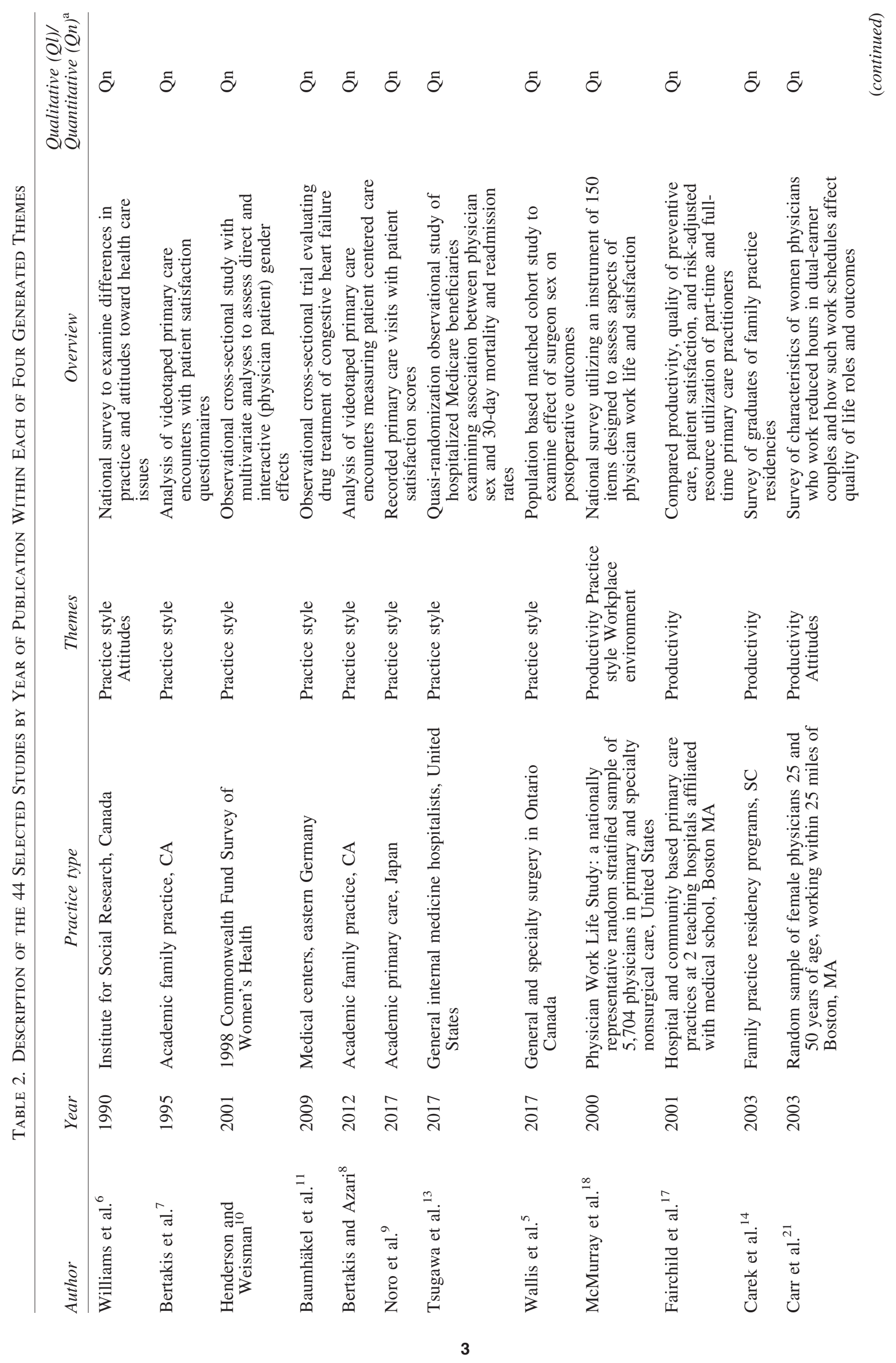




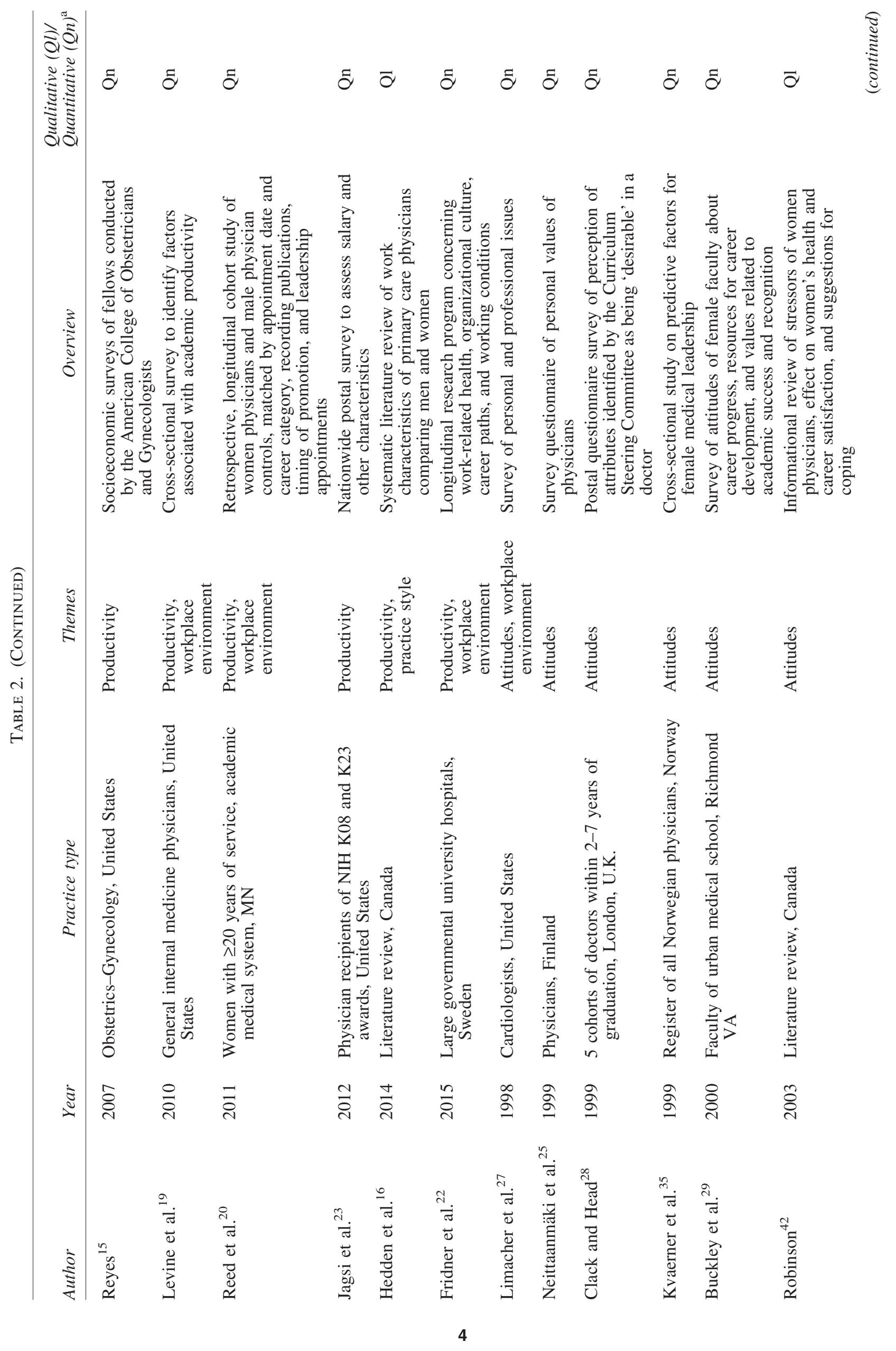




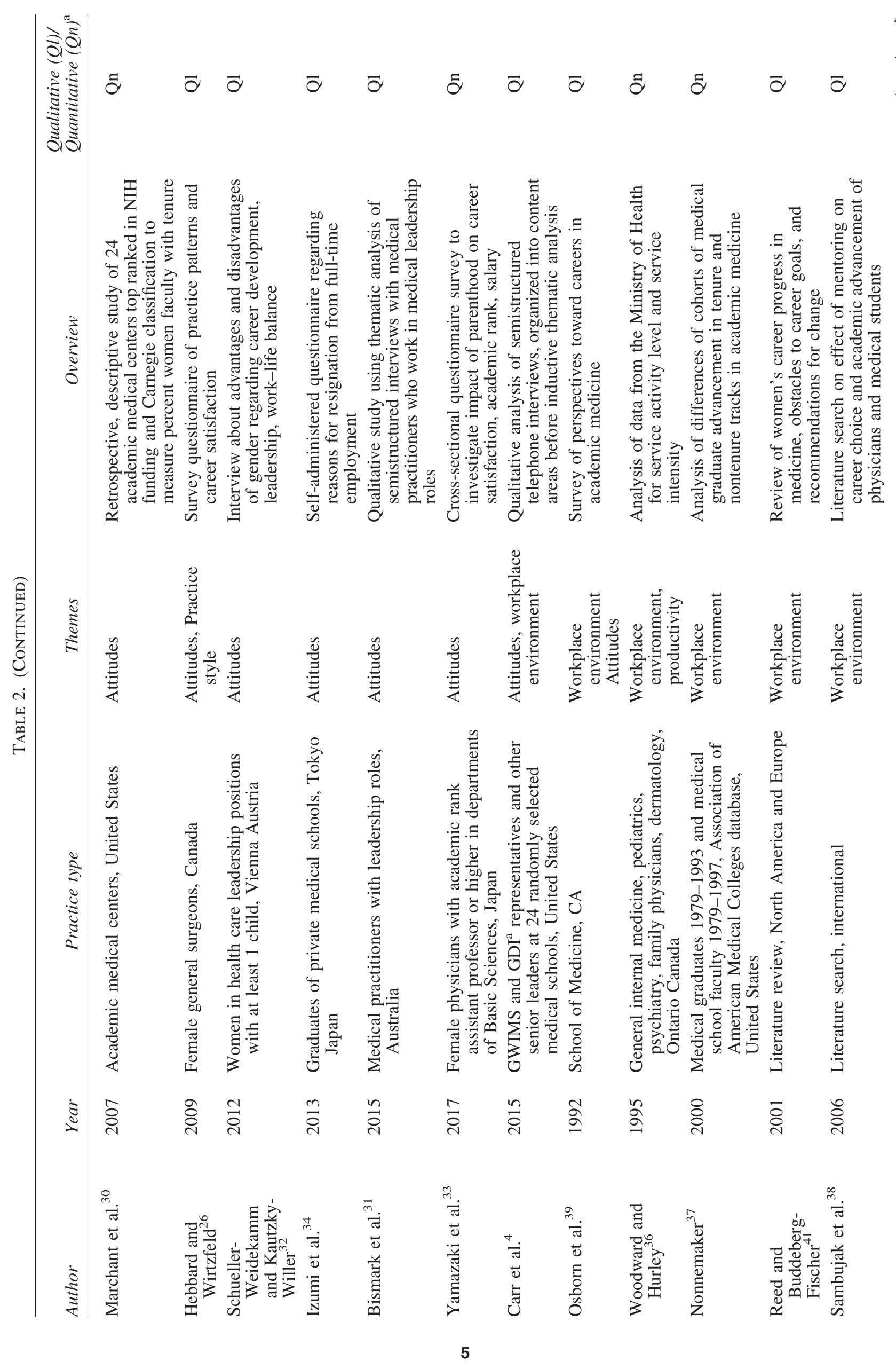




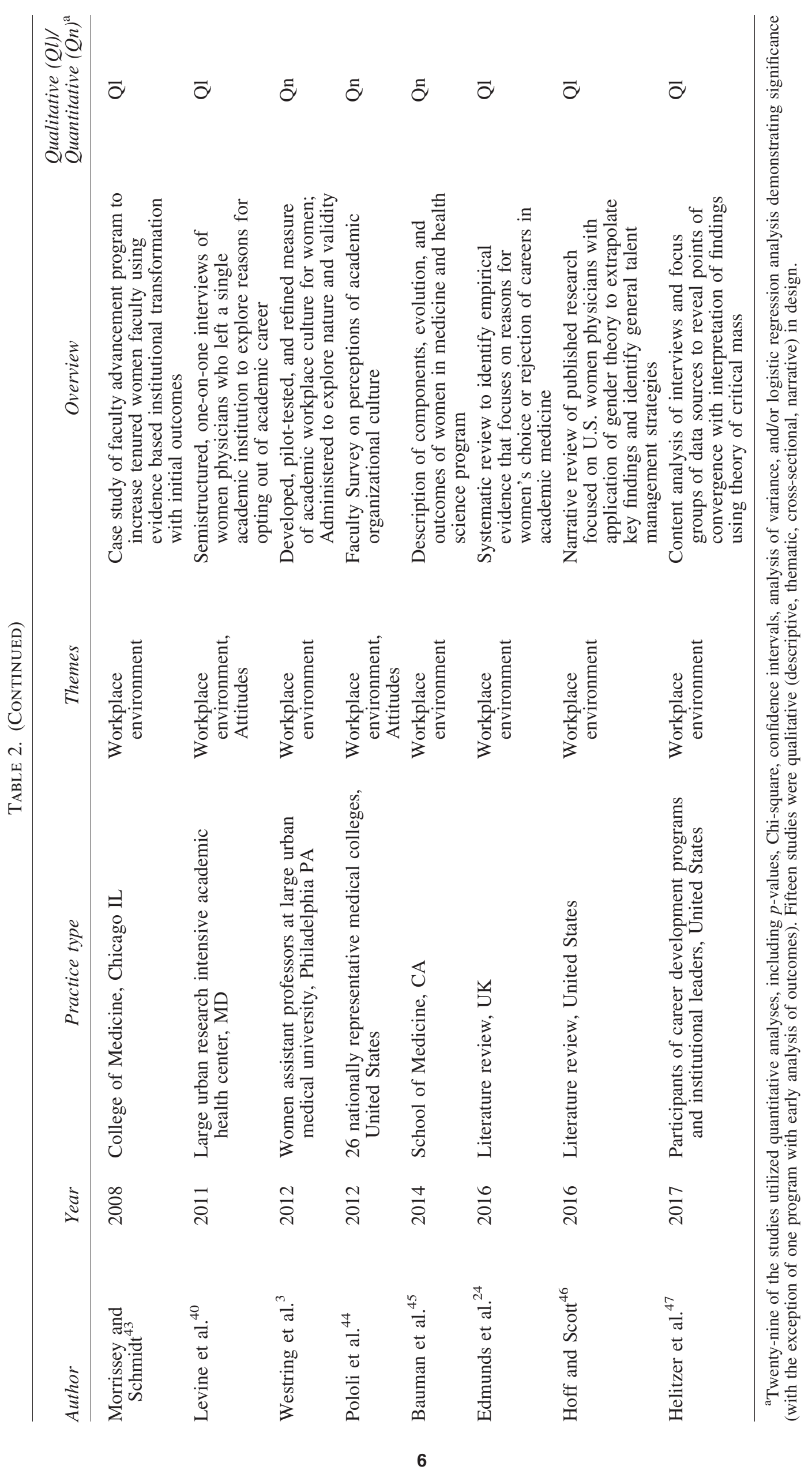


Table 3. Thematic Analysis of Findings on Women Physicians

\begin{tabular}{|c|c|c|}
\hline & Findings in current literature & Deficiencies in literature \\
\hline Practice style & $\begin{array}{l}\text { Provide more preventative care } \\
\text { Provide more counseling } \\
\text { Follow guidelines better } \\
\text { Perform fewer procedures } \\
\text { Admit fewer in-patient } \\
\text { Choose part-time }\end{array}$ & $\begin{array}{l}\text { Study designs are problematic } \\
\text { Do not capture how women physicians: } \\
\text { deliver patient care } \\
\text { set up their practice } \\
\text { relate to patients } \\
\text { Schema to assign value to practice style lacking }\end{array}$ \\
\hline Productivity & $\begin{array}{l}\text { RVU's may be greater per unit of time for "part } \\
\text { time" } \\
\text { In academic settings report more time in patient } \\
\text { care \& teaching } \\
\text { Career trajectory impacted by childbearing years } \\
\text { Lag behind men in promotion, rank, and } \\
\text { leadership }\end{array}$ & $\begin{array}{l}\text { Metrics fail to recognize quality, efficiency, \& } \\
\text { effectiveness } \\
\text { A model that accounts for career over a lifetime } \\
\text { Productivity models that focus on full scope of } \\
\text { practice \& outcomes, not just quantitative ends } \\
\text { (work hours, procedures, publications) }\end{array}$ \\
\hline Attitudes & $\begin{array}{l}\text { Attitudes of patient and colleagues toward } \\
\text { women affect job satisfaction } \\
\text { Value positive work environment \& relationships } \\
\text { over salary \& promotion } \\
\text { Lead differently } \\
\text { Underestimate their leadership potential } \\
\text { Require work-life integration }\end{array}$ & $\begin{array}{l}\text { Not enough research to fully characterize women } \\
\text { physician values } \\
\text { Studies seldom capture effects of workplace } \\
\text { attitudes }\end{array}$ \\
\hline Work environment & $\begin{array}{l}\text { Clinical environment determines practice style \& } \\
\text { career satisfaction } \\
\text { More often choose group practice, HMO, or } \\
\text { academic settings } \\
\text { Positive factors: mentorship, childcare, flexibility, } \\
\text { networking } \\
\text { Women leaving academics report less support } \\
\text { (mentors, space, funds, noncollaborative) }\end{array}$ & $\begin{array}{l}\text { Fail to capture challenges of diverse work settings } \\
\text { across specialties } \\
\text { Outcomes in work settings not designed by \& for } \\
\text { women } \\
\text { Solutions offered are designed to help women } \\
\text { physicians fit into existing gendered workplace } \\
\text { environments (e.g., flexible tenure tracks, } \\
\text { childcare, and leadership training) }\end{array}$ \\
\hline
\end{tabular}

RVU, relative value unit.

physician provided care. The researchers found that compared to men, women physicians were more likely to adhere to heart failure guidelines, resulting in better outcomes. ${ }^{11,12}$

A population based matched cohort study of 100,000 patients compared postoperative outcomes among patients treated by a man or woman surgeon. ${ }^{5}$ When matched for procedure by patient age, gender, comorbidity, surgeon volume, surgeon age, and hospital, patients treated by women surgeons had a significant decrease in 30-day mortality and similar surgical outcomes (length of stay, complications, and readmission rates). Although the mechanism for better outcomes for patients treated by women surgeons is unknown, further research is needed to determine if it may be due to greater PCC and/or superior communication. Indeed, in a more recent study using a national sample of hospitalized Medicare beneficiaries (total 1,583,028 hospitalizations), elderly patients who received care from women general internists had lower 30-day mortality and readmission rates than those cared for by men internists. ${ }^{13}$

Studies have not evaluated how men physicians specifically relate to their patients. More non U.S. researchers have addressed physician-patient interactions related to compliance with guidelines or amount of time spent asking questions, listening, and explaining.

\section{Productivity}

Clinical productivity. Gender differences in practice styles may account for variation in physician productivity (patients seen or procedures performed). Across many specialties, women physicians perform fewer procedures. In a study of 714 graduates (20.3\% women) from a residency program, women reported lower rates of procedures, whereas men physicians, with significantly higher salaries, reported doing more cesarean sections, stress testing, and endoscopies. ${ }^{14}$ In another study, women obstetrician-gynecologists $(\mathrm{OB} / \mathrm{GYN})$ performed $18 \%$ fewer procedures than their male colleagues, a gap which increased to $21 \%$ for women physicians $<40$ years. ${ }^{15}$

Many specialties lack productivity measures representative of the work performed. In a review of studies of work characteristics comparing men and women primary care practitioners (PCPs), women PCPs self-reported fewer hours of work, had fewer patient encounters, and delivered fewer services, but spent longer with their patients and dealt with more separate presenting problems in one visit. ${ }^{16}$

A study of two primary care networks found that productivity of part-time primary care physicians exceeded that of full-time primary care physicians when measured in workrelative value units. Patient satisfaction, assessed by a question rating the overall physician care received from "excellent" to "poor," was similar for part-time and full-time physicians, of whom $61 \%$ and $30 \%$ were women. ${ }^{17}$

One contributing factor to productivity is the type of patient population served. The National Physician Work Life Study found that women care for more elderly and complex patients, which require increased attention and longer consultation times. ${ }^{18}$

Academic productivity. A cross-sectional study assessing academic productivity of part-time faculty in internal medicine 
departments used a self-administered questionnaire completed by 176 physicians (91\% women). ${ }^{19}$ Findings demonstrated that women academics worked reduced hours and spent more time than men on patient care $(55 \%$ vs. $45 \%, p=0.01)$ and teaching (32\% vs. $23 \%, p=0.01)$, leaving them at a disadvantage for advancement.

Reed found that women published fewer articles throughout their early careers, but produce 1.57 more publications later than men. ${ }^{20}$ This retrospective longitudinal cohort study of 25 women physicians assessed number of publications, timeline of promotions, and leadership appointments through curriculum vitae analysis. Carr also found that women publish less, focusing instead on fewer, more distinguishable articles than men. ${ }^{21}$ This study evaluated the work hours, salaries, career satisfaction, and quality of life for a random sample of women physicians working in Boston. A longitudinal study of physicians working in large hospitals showed that control at work was positively associated with a greater number of publications for men physicians, whereby exhaustion had a negative impact on publications for women physicians. ${ }^{22}$

Although women in academic medicine contribute significantly to teaching and administrative duties, promotion is often based on the number of publications, grants, and leadership positions. The traditional performance model devalues the skills and range of tasks assigned to women in medical centers. Women physicians typically receive limited start-up packages, less grant funding, lower salary, and have fewer mentorship opportunities for developing a research career. $^{23,24}$

\section{Attitudes}

Men and women physicians differ in perception of their role as a physician and the workplace in which they practice. A Finnish study reported that women doctors value pleasant work environments and friendly colleagues, while men doctors value higher pay and success. ${ }^{25}$ In a survey of 85 Canadian women surgeons on work hours and duties, family and social obligations, and career satisfaction, job satisfaction was high; however, participants reported lower personal and parenting satisfaction. ${ }^{26}$

These results were echoed by the American College of Cardiology (ACC) Professional Life Survey. ${ }^{27}$ Five hundred eighteen women and 546 age-matched men cardiologists were asked about career path and satisfaction, family responsibilities, effects of discrimination, and job negotiation. Starting salary and time to promotion were more important to men and reduced work hours more important to women. Women were more concerned about radiation exposure, more likely to believe that family responsibilities hindered their professional work, and more likely to report experiencing gender discrimination.

Another attitudinal variable is confidence in certain elements of practice. In comparing responses from women and men, one study showed differences in nine self-attitudes, relational attributes, and ethics of care. ${ }^{28}$ Women were more confident in their ability to work on a team and creating positive interpersonal relationships. Men expressed confidence in their leadership potential, tolerance of ambiguity and uncertainty, and spirit of curiosity.

Buckley surveyed 567 medical faculty members (33\% women) on personal rate of career progress, family respon- sibilities, mentoring, understanding of promotion, academic status, and time for scholarly work. ${ }^{29}$ Women reported fewer leadership positions and valued leadership less than men. Overall, women physicians rate themselves lower on leadership ability compared to men. Being a leader is associated with stereotypic male-gender traits, that is, strength, confidence, and power which manifests as an internalized structural barrier impeding women's advancement. ${ }^{30,31}$

Interviews with Austrian women physician mothers in leadership positions document the importance of supportive partners, family, and friends. ${ }^{32}$ Women clinician mothers tend to change their workplace setting from academic hospitals to general hospitals, or full time to part time, to balance work and family responsibilities effectively. ${ }^{33,34}$ Kvaerner surveyed 13,844 practicing Norwegian physicians (28\% women, mean age 49.7) to assess factors predicting women medical leadership. Controlling for age and current post, researchers found a slight increase in women's leadership over time, attributed to a greater number of women entering the field. ${ }^{35}$

\section{The workplace environment}

Women physicians seek jobs that allow greater control, predictability, and flexibility. In Ontario, women were more likely to work in group practice, a health maintenance organization, or an academic center, while men chose solo practice. ${ }^{36}$ Women enter academic medicine at higher rates than men, but are less likely to advance to senior ranks. ${ }^{37}$

Mentoring programs influence physician choice of setting, satisfaction, and success. Existing mentorship efforts are limited and studies evaluating their effectiveness often methodologically inadequate. ${ }^{38} \mathrm{~A}$ review of women's attitudes toward academic medicine careers at a major university found that men were three times more likely than women to report relationships with mentors as a positive influence on their careers. ${ }^{39}$

The ACC Professional Life Survey reported that women cardiologists found their mentors less helpful with career tracks. ${ }^{27}$ Early-career women who left academia reported lack of support, lack of role models, and a noncollaborative work environment seeming to favor men faculty. ${ }^{40}$ Based on interviews, this study recommended flexible tenure tracks, daily onsite childcare, more robust academic support, and collaborative social networks, as ways to help women physicians adapt to workplace demands. Reed found that while many support strategies focus on women's leadership development or work-life balance, there is little regard to unfavorable organizational structures in medicine. ${ }^{41}$

Gender stereotyping has an impact on the workplace experience of women physicians. Gender stereotypes manifest in unconscious and conscious assumptions, including in the language of performance evaluation and promotion. ${ }^{30}$ Robinson suggests that "feminine" qualities such as empathy and longer patient consultations provide better experience for patients but have a negative connotation for efficiency or generation of income. ${ }^{42}$

Other research suggests new possibilities for redefinition of objectives, measures, and language according to the values, attitudes, and experiences of women physicians. One group described a novel program to promote leadership diversity. ${ }^{43}$ This multifaceted approach included leadership 
seminars, departmental transformation, policy reform, and advocacy to enhance the status of women, striving for gender parity through system changes and individual empowerment.

A survey of men and women full-time faculty from U.S. medical schools was analyzed by factor analysis on items related to institutional culture to generate content-based scales. ${ }^{44}$ Gender was a significant predictor of perceptions in six dimensions-self-efficacy for career advancement, relatedness/inclusion, value alignment, perceptions of equity, work-life integration, and perception of institutional change efforts for diversity. These findings endorse the realization of women physicians' potential and full contribution to shaping academic medicine.

Women in medicine programs can improve recruitment and retention and provide opportunities for networking, mentorship, and career development. ${ }^{45}$ Hoff and Scott conducted a narrative review of women physicians and, applying ideas from gender theory, identified key findings related to three issues: satisfaction, role challenges, and trade-offs. ${ }^{46}$ Viewing doctors as talent management, they found that gender is overwhelmed by socialization and the creation of a dominant professional identity. Helitzer, in a content analysis of career development program participant interviews and focus groups, found institutional barriers and sociocultural environment to be formidable obstacles, stalling transformational effects expected from achieving a critical mass of women faculty. ${ }^{47}$

Instead of relying on this critical mass (such as $34 \%$ of women who are academic medical faculty), Helitzer's evidence argues for "critical actor" leaders to catalyze cultural transformation of academic medicine. Essentially, critical actors are individuals with the commitment, determination, and power to create gender equity by means of national leadership or by their institutional positions (chancellors, deans, and department chairs). They can drive organizational change leading to greater recruitment, satisfaction, and promotion of women.

Westring et al. had earlier identified four facets conducive to women's success in academic medicine settings: equal access to opportunities and resources, encouragement of work-life balance, eliminating gender biases, and a supportive chair/chief. ${ }^{3}$ In addition, they developed and validated measures to the supportiveness of the workplace culture and interventions to improve these areas.

\section{Discussion}

Overall, existing studies confirm gender differences in women physicians' work habits and suggest that understanding their effects requires more extensive research (Table 3). In this review of the work habits of women physicians, focusing on four areas, we found that women physicians provide more preventive care and counseling, including increased PCC, and follow guidelines better, which has been associated with improved outcomes. Women physicians report more time in patient care and teaching in academic settings and publish fewer more distinguishable articles with an increase later in their careers. They value positive work environments, lead differently, and require work-life integration. They often choose group practice or that which offers more control and flexibility, yet do not advance in rank in academic settings. They demonstrate values, such as empathy, that enhance the patient experience, but do not align with existing productivity measures and promotion pathways.

Gender perspectives on the medical workplace call attention to the importance of sex (biological differences) and gender (meanings attached to the sexes within a particular social system) as factors influencing outcomes for physicians, as well as patients. Dominant groups typically have power to shape expectations, rules, and norms consistent with their own interests, and power affects ability to attain objectives, whether to change or maintain existing arrangements. ${ }^{48}$

Social institutions and constituent organizations are not gender neutral; in medicine, gender matters. The traditionally male-defined medical workplace has not been sufficiently responsive to women physicians' distinct needs and values. Gender is encoded in descriptions of the conditions of medical work, the attributes of successful practitioners, and the character of leadership. Both overt and subtle institutional and interpersonal gender discrimination are encountered over the course of women's medical careers. ${ }^{49}$

Women are disproportionately in medical specialties that confer less prestige. With surgery as a benchmark, the most prestigious specialties are often described in masculine terms as the toughest, riskiest, technically demanding, invasive, and hands-on types of practice. A 2014 Association of American Medical Colleges (AAMC) report noted that $38 \%$ of surgery and $37 \%$ of anesthesiology residents were women compared to $82 \%$ of $\mathrm{OB} / \mathrm{GYN}$ and $71 \%$ of pediatrics. ${ }^{2}$ Individual preference alone does not explain examples such as anesthesiology, a medical specialty with a relatively manageable schedule still largely selected by men.

Many women work part-time hours, especially early in their careers during childbearing years. This is a critical time for developing clinical practice and/or establishing research and obtaining funding. Part-time employment influences productivity, negatively affecting a woman's career path. Part-time professionals are not paid an hourly rate equivalent to the hourly compensation of full-time peers nor are they eligible for conference/educational time, and availability of mentoring is adversely affected.

Using part-time work hours or fewer cases as performance indicators results in incorrect interpretation of productivity among women physicians. These measures do not account for the scope and quality of patient care, strong teaching and committee work, or increased patient outcomes and satisfaction. Manji argued that such thinking fails to recognize standards of quality, efficiency, and effectiveness in health care delivery. ${ }^{50}$ Innovative approaches better defining success in the workplace are needed.

Current focus on patient-reported outcome measures, with patients evaluating services received, may encourage introduction of new criteria, including measures of indirect and direct effects of communication processes on health outcomes. ${ }^{51}$ Emerging emphasis on value of care may prompt further refinement of performance assessment, which can benefit from longitudinal in-depth analysis of work habits, attitudes, and experiences of women physicians and realistic consideration of obstacles they face.

Men are increasingly choosing to work part-time to balance work-life responsibilities and rewards. ${ }^{17,52}$ Maiorova's longitudinal study found both men and women searching for practice settings that offer more time for leisure activities, 
flexibility, and sharing of clinic tasks. ${ }^{53}$ Boulis and Jacobs noted that recent cohorts of physicians entering the medical profession aspire to have a long-term professional career that does not eclipse their lives. ${ }^{1}$ Preserving elements of control and flexibility in work hours is especially important to retain women physicians.

Pursuit of leadership positions has been discussed in medicine as related to institutional factors and disproportional family responsibilities. ${ }^{54,55}$ When women do assume leadership positions, they more often express preferences for collaboration and relationship building. Revising how leadership is defined and identifying, encouraging, and rewarding women's leadership styles in academic and clinical medicine would be beneficial. Greater awareness of unconscious biases in selecting leaders and concerted efforts to recruit and retain women in leadership positions are basic steps to encourage gender equity. ${ }^{56}$ Women's leadership styles will likely improve future delivery of health care as there is increasing emphasis on multidisciplinary medical teams. ${ }^{57-59}$

The gendered workplace creates additional obstacles and stressors for women physicians that erode careers, with important implications for workforce planning. Lack of congruence between practice values and institutional performance evaluation takes a toll on women physician career satisfaction. Understanding attitudes and values of women physicians and supporting them with appropriate resources will help women physicians achieve better work-life integration and enable them to practice medicine more effectively. This can be achieved only with changes in the medical workplace rather than relying on adaptation of women physicians to traditional expectations.
Collectively, women physicians can reshape the medical system to fully appreciate and utilize their skills. For example, women's health issues and women physicians' careers are addressed by organizations such as the American Medical Women's Association, the Medical Women's International Association, and the American Medical Association's Women Physicians Section. Women physician leadership and advocacy have already generated far-reaching advances in women's health by expanding the definition of health and improving health care research, education, and practice.

Women physicians are highly educated and competent professionals seeking options different from the traditional male-defined model of medical careers. Remedies for gender-driven lower rates of promotion and pay, continued bias, and discrimination in medicine are expected to improve the medical system at large. More broadly, the concept of "constrained choice" links organizational structure and processes to individual experience and to a larger context of social institutions and policies. ${ }^{48}$ Constrained choice describes those personal and societal factors that influence women's career choices especially insofar as society continues to place a disproportionate emphasis on women's domestic responsibilities, and women, more so than men, are forced to balance conflicting responsibilities of home, life, and career. In the workplace, constrained choice results from norms that have historically been developed to favor the patterns and interests of men who, resultingly, may disproportionately hold positions of power affecting women's choices. Accordingly, Table 4 illustrates different levels of $4 \mathrm{~T} 4$ intervention that might be used to minimize gender constraints and foster opportunity. ${ }^{60-68}$

TAble 4. Major Domains for Intervention Moving Forward ${ }^{3,4,60-68}$

\begin{tabular}{|c|c|c|}
\hline Domain & Key factors & Areas for change \\
\hline Societal context & $\begin{array}{l}\text { Law, government policy \& practice, } \\
\text { cultural beliefs, gender socialization, } \\
\text { media representation }\end{array}$ & $\begin{array}{l}\text { Responsiveness to gender issues } \\
\text { Equal access to research funding \& resources } \\
\text { Setting research priorities \& evaluating interventions } \\
\text { Sociopolitical advocacy }\end{array}$ \\
\hline Medicine & $\begin{array}{l}\text { Traditional expectations; current } \\
\text { organization \& performance } \\
\text { Workplace: structure, <-> Family: roles, } \\
\begin{array}{ll}\text { culture, procedures, } & \text { values, } \\
\text { interpersonal } & \text { circumstances. } \\
\text { relations. } & \end{array}\end{array}$ & $\begin{array}{l}\text { Legitimizing work-life balance } \\
\text { Fully accommodating pregnancy, breastfeeding, and } \\
\text { childcare } \\
\text { Pausing tenure clock, flexibility policies, parental } \\
\text { leave } \\
\text { Monitoring \& correcting gender gap in pay \& } \\
\text { promotion } \\
\text { Amending productivity measures } \\
\text { Programs fostering leadership, sponsorship, } \\
\text { mentorship. } \\
\text { Education/training on gender } \\
\text { bias/discrimination/harassment } \\
\text { Strategies to recruit, engage, retain }\end{array}$ \\
\hline $\begin{array}{l}\uparrow \\
\text { Individual }\end{array}$ & $\begin{array}{l}\text { + Personal satisfaction } \\
\text { + Sense of agency and control } \\
\text { + Perceived identity compatibility } \\
\text { + Sense of belonging } \\
\text { + Role models } \\
\text { + Perceived interpersonal support } \\
\text { - Role strain, exhaustion, burnout } \\
\text { - Conflicting work \& family demands } \\
\text { +- Lived experience of rewards \& costs }\end{array}$ & $\begin{array}{l}\text { Individualized career plans } \\
\text { Prioritizing limited resources } \\
\text { Seeking additional training in leadership, practice } \\
\text { management, negotiation } \\
\text { Finding or becoming a mentor/sponsor } \\
\text { Working for gender equity, alone or with others }\end{array}$ \\
\hline
\end{tabular}




\section{Limitations}

Considering potential selection and interpretation biases in qualitative research, and given the volume of existing studies, overlooking a relevant article must be recognized as a risk despite care taken. Particular articles can address more than one theme, and other reviewers might have identified additional or alternative patterns across studies. This particular review focuses on gender in the workplace and can serve as a guide for further study.

\section{Conclusion}

Studies of women physicians have identified challenges in medicine, with few solutions. Recommendations typically focus on molding women physicians to practice within a primarily male-oriented medical system. Mentorship programs, women physician networks, and leadership training have helped women, yet remain subject to the interpretation that women are less qualified or committed than men and, therefore, require special assistance.

This review suggests instead that women bring particular attributes and perspectives to patient care, leadership, research, and the workplace environment. Full inclusion of women physicians in medicine is more than a matter of access and numbers; it entails structural and cultural transformation. With respect to leadership, for example, it asks for a new image of a leader incorporating the values women bring with respect to communication and teamwork.

Effectively achieving gender equity requires a critical look at previous strategies and better understanding of women physicians. Limitations of existing studies range from small sample size and assessments of single institutional settings to larger scale quantitative surveys with superficial or biased measures of key variables. Different practice settings and work environments contribute to variation in stressors, mentorship, productivity, and career satisfaction.

Qualitative methods such as direct observation, focus groups, and interviews can provide more in-depth analyses of women physicians' experiences. Quantitative studies with new measures and more representative samples can provide a broader picture of gender differences in practice style, attitudes, and outcomes.

If the goal is advancement and full inclusion of women physicians, enhancing career development, addressing physician burnout, and attention to institutional factors influencing medical career productivity, satisfaction and longevity are warranted. Examination of institutional factors should recognize the perspectives and talents women bring to medicine and explore the implications of a diverse medical workplace and physician workforce.

\section{Acknowledgments}

The authors are indebted to the late Linda Brodsky, MD, for initiating the idea and helping to procure grant funding for this project, her interpretation of themes, and for her relentless pursuit to learn the voice of women physicians. The authors acknowledge Kate Butler for assistance with the literature review, Kim Templeton, MD and Dana Sue-Hardin, MD for editing assistance, and the American Medical Women's Association (AMWA) Gender Equity Task Force for their support.

\section{Author Disclosure Statement}

Roberta Gebhard, DO is the President of AMWA, serves on Board of Directors, and is Co-founder of the Gender Equity Task Force.

Wendy Bernstein, MD, MBA serves on the Board of Directors for AMWA and Co-chairs the Gender Equity Task Force.

The contents do not represent the views of the United States Government.

\section{Funding Information}

Joan F. Giambalvo Scholarship Fund for its financial grant.

\section{References}

1. Boulis AK, Jacobs JA. The changing face of medicine: Women doctors and the evolution of health care in America. Ithaca, NY: Cornell University Press, 2008.

2. Lautenberger DM, Dandar VM, Raezer CL, Sloane RA. The state of women in academic medicine: The pipeline and pathways to leadership 2013-2014. Washington, DC: Association of American Medical Colleges, 2014.

3. Westring AF, Speck RM, Sammel MD, et al. A culture conducive to women's academic success: Development of a measure. Acad Med 2012;87:1622-1631.

4. Carr PL, Gunn CM, Kaplan SA, Raj A, Freund KM. Inadequate progress for women in academic medicine: Findings from the national faculty study. J Womens Health 2015;24:190-199.

5. Wallis C, Ravi B, Coburn N, et al. Comparison of postoperative outcomes among patients treated by male and female surgeons: A population based matched cohort study. BMJ 2017;359:j4366.

6. Williams AP, Domnick-Pierre K, Vayda E, Stevenson HM, Burke M. Women in medicine: Practice patterns and attitudes. Can Med Assoc J 1990;143:194-201.

7. Bertakis KD, Helms LJ, Callahan EJ, Azari R, Robbins JA. The influence of gender on physician practice style. Med Care 1995;33:407-416.

8. Bertakis KD, Azari R. Patient-centered care: The influence of patient and resident physician gender and gender concordance in primary care. J Womens Health 2012;21:326333.

9. Noro I, Roter DL, Kurosawa S, Miura Y, Ishizaki M. The impact of gender on medical visit communication and patient satisfaction within the Japanese primary care context. Patient Educ Couns 2017;101:227-232.

10. Henderson JT, Weisman CS. Physician gender effects on preventive screening and counseling: An analysis of male and female patients' healthcare experiences. Med Care 2001;39:1281-1292.

11. Baumhäkel M, Müller U, Böhm M. Influence of gender of physicians and patients on guideline-recommended treatment of chronic heart failure in a cross-sectional study. Eur J Heart Failure 2009;11:299-303.

12. Cowie MR, Komajda M. Quality of physician adherence to guideline recommendations for life-saving treatment in heart failure: An international survey. CFR 2017;3:130 133.

13. Tsugawa $\mathrm{Y}$, Jena $\mathrm{AB}$, Figueroa JF, et al. Comparison of hospital mortality and readmission rates for medicare patients treated by male vs female physicians. JAMA Intern Med 2017;177:206-213. 
14. Carek PJ, King DE, Hunter M, Gilbert GE. Practice profiles, procedures, and personal rewards according to the sex of the physician. South Med J 2003;96:767-771.

15. Reyes JW. Gender gaps in income and productivity of obstetricians and gynecologists. Obstet Gynecol 2007;109: 1031-1039.

16. Hedden L, Barer ML, Cardiff K, et al. The implications of the feminization of the primary care physician workforce on service supply: A systematic review. Hum Resour Health 2014;12:32.

17. Fairchild DG, Sax McLoughlin K, Gharib S, et al. Productivity, quality, and patient satisfaction: Comparison of part-time and full-time primary care physicians. J Gen Inter Med 2001;16:663-667.

18. McMurray JE, Linzer M, Konrad TR, et al. The work lives of women physicians: Results from the physician work life study. J Gen Inter Med 2000;15:372-380.

19. Levine RB, Mechaber HF, Bass EB, Wright SM. The impact of working part-time on measures of academic productivity among general internists. J Womens Health 2010; 19:1995-2000.

20. Reed DA, Enders F, Lindor R, McClees M, Lindor KD. Gender differences in academic productivity and leadership appointments of physicians throughout academic careers. Acad Med 2011;86:43-47.

21. Carr PL, Gareis KC, Barnett RC. Characteristics and outcomes for women physicians who work reduced hours. J Womens Health 2003;12:399-405.

22. Fridner A, Norell A, Akesson G, Gustafsson SM, Tevik Lovseth L, Schenck-Gustafsson K. Possible reasons why female physicians publish fewer scientific articles than male physicians-a cross-sectional study. BMC Med Educ 2015;15:67.

23. Jagsi R, Griffith KA, Stewart A, Sambuco D, DeCastro R, Ubel P. Gender differences in the salaries of physician researchers. JAMA 2012;307:2410-2417.

24. Edmunds LD, Ovseiko PV, Shepperd S, et al. Why do women choose or reject careers in academic medicine? A narrative review of empirical evidence. Lancet 2016;388: 2948-2958.

25. Neittaanmäki L, Gross EB, Virjo I, Hyppölä H, Kumpusalo E. Personal values of male and female doctors: Gender aspects. Soc Sci Med 1999;48:559-568.

26. Hebbard PC, Wirtzfeld DA. Practice patterns and career satisfaction of Canadian female general surgeons. Am J Surg 2009;197:721-727.

27. Limacher M, Zaher C, Walsh M, et al. The ACC professional life survey: Career decisions of men and women in cardiology. J Am Col Cardiol 1998;32:827-835.

28. Clack GB, Head JO. Gender differences in medical graduates' assessment of their personal attributes. Med Educ 1999;33:101-105.

29. Buckley LM, Sanders K, Shih M, Kallar S, Hampton C. Obstacles to promotion? values of women faculty about career success and recognition. Acad Med 2000;75:283-288.

30. Marchant A, Bhattacharya A, Carnes M. Can the language of tenure criteria influence women's academic advancement? J Womens Health 2007;16:998-1003.

31. Bismark M, Morris J, Thomas L, et al. Reasons and remedies for underrepresentation of women in medical leadership roles: A qualitative study from Australia. BMJ Open 2015;5:e009384.

32. Schueller-Weidekamm C, Kautzky-Willer A. Challenges of work-life balance for physicians/mothers working in leadership positions. Gender Med 2012;9:244-250.
33. Yamazaki Y, Uka T, Marui E. Professional fulfillment and parenting work-life balance in female physicians in basic sciences and medical research: A nationwide crosssectional survey of all 80 medical schools in Japan. Hum Resour Health 2017;15:65.

34. Izumi M, Nomura K, Kigaki Y, et al. Gender role stereotype and poor working condition pose obstacles for female doctors to stay in full-time employment: Alumnae survey from two private medical schools in Japan. Tohoku J Exp Med 2013;229:233-237.

35. Kvaerner KJ, Aasland OG, Botten GS. Female medical leadership: Cross sectional study. Br Med J 1999;318: 91-94.

36. Woodward CA, Hurley J. Comparison of activity level and service intensity of male and female physicians in five fields of medicine in Ontario. CMAJ 1995;153:1097-1106.

37. Nonnemaker L. Women physicians in academic medicine. N Engl J Med 2000;342:399-405.

38. Sambujak D, Straus SE, Marusic A. Mentoring in academic medicine: A systematic review. JAMA 2006;296:11031115.

39. Osborn EHS, Ernster VL, Martin JB. Women's attitudes toward careers in academic medicine at the University of California, San Francisco. Acad Med 1992;67:59-62.

40. Levine RB, Lin F, Kern DE, Wright SM, Carrese J. Stories from early-career women physicians who have left academic medicine: A qualitative study at a single institution. Acad Med 2011;86:752-758.

41. Reed V, Buddeberg-Fischer B. Career obstacles for women in medicine: An overview. Med Educ 2001;35:139-147.

42. Robinson GE. Stresses on women physicians: Consequences and coping techniques. Depress Anxiety 2003; 17:180-189.

43. Morrissey CS, Schmidt ML. Fixing the system, not the women: An innovative approach to faculty advancement. J Womens Health 2008;17:1399-1408.

44. Pololi LH, Civian JT, Brennan RT, Dottolo AL, Krupat E. Experiencing the culture of academic medicine: Gender matters, a national study. J Gen Intern Med 2012;28:201207.

45. Bauman MD, Howell LP, Villablanca AC. The women in medicine and health science program: An innovative initiative to support female faculty at the University of California Davis School of Medicine. Acad Med 2014;89:1462-1466.

46. Hoff T, Scott S. The gendered realities and talent management imperatives of women physicians. Health Care Manage Rev 2016;41:189-199.

47. Helitzer DL, Newbill SL, Cardinali G, Morahan PS, Chang $S$, Magrane D. Changing the culture of academic medicine: Critical mass or critical actors? J Womens Health 2017;26: 540-548.

48. Kramer L, Beutel A. The sociology of gender: A brief introduction. Fourth edition, USA: Oxford University Press, 2014.

49. Rouse, LP. Understanding how women physicians view gender and the workplace: Using field observation, informal interviews, and organizational websites. SAGE Research Methods Cases 2014; London, UK: SAGE.

50. Manji F, Vukin I, Lent B, Herbert C. Better doctor efficiency is the real key to better productivity. Med Educ 2009;43: 1019.

51. Street RL. Gender differences in health care provider-patient communication: Are they due to style, stereotypes, or accommodation? Patient Educ Counsel 2002;48:201-206. 
AU4 52. Office for National Statistics 2014; Available at: www.ons .gov.uk

53. Maiorova T, Stevens F, van der Velden L, Scherpbier A, van der Zee J. Gender shift in realization of preferred type of gp practice: Longitudinal survey over the last 25 years. BMC Health Serv Res 2007;7:111.

54. Carnes M, Morrissey C, Geller SE. Women's health and women's leadership in academic medicine: Hitting the same glass ceiling? J Womens Health 2008;17:14531462.

55. Tarr-Whelan L. Women lead the way: Your guide to stepping up to leadership and changing the world. San Francisco: Berrett-Koehler Publishers. 2009.

56. Girod S, Fassiotto M, Grewal D, et al. Reducing implicit gender leadership bias in academic medicine with an educational intervention. Acad Med 2016;91:1143-1150.

57. Levinson W, Lurie N. When most doctors are women: What lies ahead? Ann Intern Med 2004;141:471.

58. Kuhlmann E, Ovseiko PV, Kurmeyer C, et al. Closing the gender leadership gap: A multi-centre cross-country comparison of women in management and leadership in academic health centres in the European Union. Hum Resour Health 2017;15:2

59. Pingleton SK, Jones EV, Rosolowski TA, Zimmerman MK. Silent Bias: Challenges, Obstacles, and Strategies for Leadership Development in Academic Medicine-Lessons From Oral Histories of Women Professors at the University of Kansas. Acad Med 2016;91:1151-1157.

60. Freund KM, Raj A, Kaplan SE, et al. Inequities in Academic Compensation by Gender: A Follow-up to the National Faculty Survey Cohort Study. Acad Med 2016;91: 1068-1073.

61. Choo EK, Kass D, Westergaard M, et al. The Development of Best Practice Recommendations to Support the Hiring, Re- cruitment, and Advancement of Women Physicians in Emergency Medicine. Acad Emerg Med 2016;23:1203-1209.

62. Bates C, Gordon L, Travis E, et al. Striving for gender equity in academic medicine careers: A call to action. Acad Med 2016;91:1050-1052.

63. Barfield WL, Plank-Bazinet JL, Austin Clayton J. Advancement of Women in the Biomedical Workforce: Insights for Success. Acad Med 2016;91:1047-1049.

64. Travis EL, Doty L, Helitzer DL. Sponsorship: A path to the academic medicine C-suite for women faculty? Acad Med 2013;88:1414-1417.

65. Valantine H, Sandborg CI. Changing the culture of academic medicine to eliminate the gender leadership gap: 50/ 50 by 2020. Acad Med 2013;88:1411-1413.

66. Fassiotto M, Hamel EO, Ku M, et al. Women in Academic Medicine: Measuring Stereotype Threat Among Junior Faculty. J Womens Health 2016;25:292-298.

67. Hill EV, Wake M, Carapinha R, et al. Rationale and design of the women and inclusion in academic medicine study. Ethn Dis 2016;2:245-254.

68. Rosenthal L, Levy SR, London B, Lobel M, Bazile C. In Pursuit of the MD: The Impact of Role Models, Identity Compatibility, and Belonging Among Undergraduate Women. Sex Roles 2013;68:464-473.

Address correspondence to: Wendy K. Bernstein, MD, MBA, FASA, FAMWA Department of Anesthesiology and Perioperative Medicine University of Rochester Medical Center 601 Elmwood Avenue, Box 604 Rochester, NY 14642

E-mail: wendy_bernstein@urmc.rochester.edu 


\section{AUTHOR QUERY FOR JWH-2018-7290-VER9-ROUSE_1P}

AU1: Please identify (highlight or circle) all authors' surnames for accurate indexing citations.

AU2: Abstract has been taken from the metadata file. Please check.

AU3: Keywords have been taken from PDF. Please check.

AU4: Please provide the date you last viewed the website for Reference 52.

AU5: Figure 1 has been numbered as Table 1 and also earlier Tables 1-3 have been changed to Tables 2-4. Please check. 